\title{
Condomínios e Gated Communities: por uma antropologia das novas composições urbanas
}

\section{Cristina Patriota de Moura}

\section{(2) OpenEdition \\ 1 Journals}

Edição electrónica

URL: http://journals.openedition.org/aa/970

DOI: 10.4000/aa.970

ISSN: 2357-738X

Editora

Programa de Pós-Graduação em Antropologia Social (UnB)

\section{Edição impressa}

Data de publição: 1 dezembro 2010

Paginação: 209-233

ISSN: 0102-4302

\section{Refêrencia eletrónica}

Cristina Patriota de Moura, «Condomínios e Gated Communities: por uma antropologia das novas composições urbanas», Anuário Antropológico [Online], v.35 n.2 | 2010, posto online no dia 04 novembro 2015, consultado o 28 abril 2021. URL: http://journals.openedition.org/aa/970 ; DOI: https:// doi.org/10.4000/aa.970

\section{(c) (i) $\ominus$}

Anuário Antropológico is licensed under a Creative Commons Atribuição-Uso Não-Comercial-Proibição de realização de Obras Derivadas 4.0 International. 


\title{
Condomínios e Gated Communities: por uma antropologia das novas composições urbanas*
}

\author{
Cristina Patriota de Moura \\ Departamento de Antropologia/UnB
}

\begin{abstract}
Condomínio já foi sinônimo de luxo. Cansada de pagar aluguel no Plano Piloto, a classe média do Distrito Federal recorreu às ocupações irregulares e construiu parcelamentos requintados, com casas grandes e suntuosas. Mas a realidade agora é outra. Com o fim da distribuição e venda de lotes nas regiões administrativas, a população de baixa renda ocupou ilegalmente grandes áreas do DF. Hoje, 69\% dos moradores dos condomínios têm renda inferior a cinco salários mínimos (R \$1.750,00). As ocupações informais de classe alta representam apenas 1\% dos 379 parcelamentos urbanos.

Correio Braziliense, 22/08/2006
\end{abstract}

O texto acima, que inicia uma das 44 matérias publicadas no jornal de maior circulação do Distrito Federal sob a rubrica Condomínios no ano de 2006, aponta para uma série de questões que considero relevante discutir neste trabalho. Primeiramente, o lugar de destaque no discurso público de um termo que indica certo tipo de configuração espacial. Essa configuração espacial, o "condomínio", que também é, nesse caso, chamado de condomínio horizontal, ou condomínio irregular, aponta para parcelamentos de solo formados por unidades domiciliares, que muitas vezes se destacam de outros parcelamentos por possuírem muros perimetrais comuns e áreas de circulação interna próprias, de acesso restrito. Há também, em geral, associações de moradores que impõem determinadas regras de conduta internas a esses espaços. Esse tipo de espaço residencial vem proliferando já há mais de duas décadas, mas é a partir da década de 1990 que os "condomínios" ganham destaque nos discursos públicos não só da mídia, mas também das ciências sociais e não só no Brasil, mas em diversas partes do globo.

Este trabalho visa apresentar algumas das discussões acadêmicas que têm aparecido na literatura internacional acerca das "gated communities", nome que também tem sido usado para designar nossos "condomínios". O objetivo é problematizar a utilização de conceitos e modelos construídos a partir de casos específicos para compreender outros processos também específicos. Não se trata de negar a validade de análises macro e propor uma pulverização dos estudos onde 
a perspectiva comparada é abandonada em nome da etnografia como valor em si, mesmo porque a complementaridade entre os estudos "de perto e de dentro" e os "de longe e de fora” já foi devidamente discutida (Magnani, 2002). A proposta é utilizar o caso das "gated communities" e dos "condomínios" para pensar combinações de forças que, para além de serem atualizações locais de modelos globais ou casos à parte que têm valor intrínseco, rompam com dicotomias do estilo particular/ universal ou unidade/diversidade, com as quais a antropologia tem lidado desde seus primórdios. Trata-se de pensar em formas de associação (Tarde, 1895; Latour, 2005 e 2006) que produzem assemblages ou composições (Latour, 2005; Ong e Collier, 2005; Deleuze, 1980; DeLanda, 2006; Sassen, 2006) que sempre estarão em movimento, já que seus elementos são sempre atores que efetuam transformações e não simplesmente servem de elos intermediários entre formas cristalizadas.

\section{Os EUA e a gênese do termo "gated community"}

Com enfoques diferentes, profissionais de diversas áreas têm se debatido em torno do significado de parcelas cada vez maiores das populações urbanas morarem, por escolha própria, em lugares segregados e com aparatos de segurança particulares. $O$ termo que se cunhou internacionalmente para designar conjuntos de unidades residenciais com perímetros definidos por muros, cercas e aparatos de segurança privados é o termo "gated community", utilizado pelos urbanistas norte-americanos Edward Blakely e Gail Snyder, autores do livro Fortress America. Gated Communities in the United States, que se tornou referência obrigatória para todos que estudam o fenômeno. O livro, lançado em 1997, causou impacto, principalmente, pelos números que apresentava. Os autores falavam de três milhões de domicílios norte-americanos em gated communities. Há dados mais recentes que indicam que mais de 16 milhões de pessoas vivem naquele tipo de ambiente nos Estados Unidos. ${ }^{1}$ Os autores, por sua vez, dizem ter simplesmente reproduzido o termo que já era amplamente utilizado em propagandas imobiliárias que apelavam para o desejo dos norte-americanos de viverem em pequenas "comunidades".

As residências que estamos discutindo não são edifícios em condomínio com múltiplas unidades e alta densidade, com sistemas de segurança e porteiros, nos quais os guardas e os portões impedem acesso a saguões de entrada, corredores e estacionamentos. Comunidades muradas são diferentes: seus muros e grades impedem o acesso público a ruas, calçadas, parques, praias, rios, trilhas e áreas de recreação - sendo esses recursos que sem os muros ou portões seriam abertos e compartilhados por todos os cidadãos de uma localidade. (Blakely e Snyder, 1997:2 - tradução livre) 
Não somente os agentes imobiliários, mas as próprias análises acadêmicas norte-americanas estão marcadamente pautadas na ideia-valor "comunidade", como atestam discussões acerca dos tipos de vínculos entre vizinhos e teses como a do "minimalismo moral", proposta por Baumgartner ${ }^{2}$ (1988) e defendida por Low $(2003,2006)$ que, em trabalhos mais recentes, vem também argumentando que Community é uma categoria vazia, apesar de compartilhada e com forte carga emotiva para residentes de gated communities e cooperativas em Nova Iorque (Low, 2009). A ideia de que áreas residenciais devem ser comunidades de interconhecimento face a face e ajuda mútua persiste como um ideal a ser alcançado mesmo em meio a todas as discussões sobre cidades globais (Sassen, 1991) e espaços de fluxos na era informacional (Castells, 2006). A existência de publicações como o periódico City and Community, organizado pela American Sociological Association, mantém vivo um debate que tem um forte lado normativo e saudosista e apresenta reiteradamente artigos que dialogam com o "problema" do enfraquecimento de sentimentos comunitários. ${ }^{3}$ O resumo do artigo de Ryle (2005), publicado no mesmo volume que traz um trabalho de Romig sobre gated communities, é ilustrativo neste sentido:

Propomos um modelo ideológico/cosmológico para complementar três respostas que têm sido oferecidas para a Questão Comunitária: alegações de que a comunidade está perdida, salva ou libertada. Propomos a hipótese de que o sistema educacional dos EUA inculca uma ideologia individualista e dispõe pessoas altamente instruídas a um sentido de comunidade mais fraco. Também aventamos a hipótese de que a cosmologia moral teologicamente modernista é inerentemente individualista em relação à cosmologia ortodoxa e inclina aqueles que a professam a ter um menor espírito comunitário. (Ryle, 2005:53 - tradução livre)

O termo community, quando utilizado em propagandas imobiliárias nos EUA, é um termo poderoso, que remete a uma gama de ideias e valores que se relacionam à vida associativa, ao bem-estar da família nuclear, ao empreendedorismo individual e à própria manutenção de valores democráticos igualitários. Porém, essas communities que estão sendo vendidas não são aquelas pequenas cidades da Nova Inglaterra onde os puritanos instituíram uma sociedade: são incorporações imobiliárias recentes, que se situam em espaços onde se encontram justamente os suburbs que muitos norte-americanos identificam como sendo um oposto da small town.

Rosane Prado, em sua tese de doutorado sobre a mitologia da small town nos Estados Unidos (Prado, 1993), já apresentava interessantes instrumentos para pensarmos o surgimento desses novos empreendimentos imobiliários que são as gated communities. No referido trabalho, a autora faz um apanhado das imagens 
que os norte-americanos compartilham a respeito da small town, que seria o lugar de fundação da própria sociedade norte-americana, com seus mais caros valores de individualismo, democracia e espírito comunitário. Naquele país, o termo community aparece associado a small town, sendo os dois termos usados praticamente como sinônimos, havendo uma preocupação constante com o desaparecimento tanto de um quanto de outro.

A categoria americana de "suburb" não corresponde à categoria brasileira de subúrbio (...). Nos Estados Unidos, o "suburb" é caracterizado por ser uma área basicamente residencial, criada como apêndice de uma cidade grande à qual os moradores são referidos na maior parte de suas atividades. Everett Ladd (1969), analisando as diferenças entre "cities, suburbs, small towns: three contrasting sociopolitical settings”, fala dos estereótipos em relação aos suburbs, através de duas divisões correspondentes aos mais ricos e aos mais pobres (...). no meu modo de ver, o tom de desvalorização em relação ao suburb deve-se a ele ser representado como lugar homogeneizado ao extremo, e onde, segundo os critérios americanos, tende a não haver community. (Prado, 1993:108)

Os suburbs norte-americanos, desde a explosão imobiliária que os fez crescer vertiginosamente, a partir do período pós-segunda guerra mundial, já sofreram grandes críticas por parte das elites cosmopolitas das cidades grandes e urbanistas em geral. Falou-se sobre a feiúra dos cookie-cutter houses, uma alusão à produção em série, que faz as casas parecerem biscoitos feitos com a mesma forma e, supostamente, também produz cookie-cutter people. Foi dito que os subúrbios produziam homens alienados com esposas massacradas como motoristas dos filhos, que por sua vez se tornavam adolescentes frustrados. ${ }^{4}$ Vejamos a crítica de uma dupla de urbanistas que vem fazendo sucesso nos EUA, liderando o chamado "new town movement".

O espraiamento suburbano é um crescimento canceroso, em vez de um crescimento saudável, e está destruindo a vida cívica (...). Suburbanitas sentem o que está errado com os lugares em que habitam. Trânsito, tempo de locomoção diária, e grandes distâncias de locais de compras, trabalho e lazer estão altamente cotados entre suas reclamações. Mas todos esses inconvenientes poderiam ser mais suportáveis se os subúrbios não fossem tão carentes da maioria dos sinais de comunidade (...). A estrutura do subúrbio tende a confinar as pessoas a suas casas e carros; ela desencoraja caminhadas, passeios e interações com vizinhos. O subúrbio é a última palavra em privatização, talvez, inclusive, sua consumação letal, e ainda soletra o fim da vida civil autêntica (Duany e Plater-Zyberk, 1992:1 tradução livre). 
Após fazer essa dramática constatação, os autores citam dados de uma pesquisa feita pelo Instituto Gallup:

Quando a Organização Gallup perguntou aos norte-americanos em 1989 em que tipo de lugar eles gostariam de viver, a escolha mais popular foi em uma cidade pequena. Somente $24 \%$ escolheram um subúrbio, 22\% uma fazenda e 19\% uma cidade grande. (Duany e Plater-Zyberk, 1992:1 tradução livre)

É interessante notarmos que, se o suburb é alvo de ataques, a city parece fazer ainda menos sucesso. O fato é que dados do senso de 2000 mostravam mais de $60 \%$ dos norte-americanos vivem em lugares considerados suburbs, nas áreas metropolitanas das grandes cidades. Se, por um lado, os subúrbios são criticados pela homogeneidade e falta de senso de community, os dados apresentados pelos urbanistas parecem sugerir que a grande cidade é ainda menos desejável. Tendo-se em vista a escala da sociedade moderno-capitalista, não é difícil argumentar que viver em uma pequena cidade é um sonho que dificilmente pode ser realizado por uma grande parcela da população. Viver em suburbs, portanto, mesmo tendo em vista as considerações anteriores, não é algo completamente dissociado do sonho da cidade pequena.

Foi o sociólogo Herbert Gans $(1982,1993)$ quem, de forma mais contundente, demonstrou que, se os subúrbios têm tanto apelo comercial, é porque as pessoas querem viver em suas próprias casas, com quintais para as crianças brincarem, longe do tumulto das cidades grandes e, ao mesmo tempo, com acesso a empregos e educação. Se a cidade pequena é um sonho da maioria dos norte-americanos, os subúrbios talvez sejam a forma de moradia acessível que mais se aproxima desse ideal. Porém, o fato de eles terem sofrido tantas críticas talvez tenha também permitido que novas alternativas surgissem. O que é uma gated community senão um bairro de casas recém-construídas por uma incorporadora, como os demais developments dos suburbs norte-americanos, mas circunscrito por muros?

Talvez mais do que uma questão de segregação e segurança, a ideia de community, nos Estados Unidos, possa estar relacionada à ideia de um espaço pequeno onde é possível conhecer a todos pelo nome, como no caso da small town. E essa parece ser a maior preocupação de Blakely e Snider: seriam as gated communities realmente communities?

\section{Gated Communities como fenômeno global}

Vimos que nos EUA as gated communities surgem como um desdobramento do processo de suburbanização das camadas médias. Por acreditar que o modelo norte-americano tem sido amplamente copiado, diversos autores tratam áreas residenciais muradas, incluindo os condomínios fechados que encontramos no Brasil, como mais um espécime do gênero gated community. O trecho abaixo é uma demonstração da visão homogeneizadora que vê nos condomínios um fenômeno da globalização. 
Mesmo que as gated communities latino-americanas sejam caracterizadas, até certo ponto, de acordo com padrões culturais específicos (por exemplo, com respeito à preferência por instalações de lazer), elas são prioritariamente uma expressão das influências da globalização. Em suas concepções gerais, bem como em suas condições de vida, correspondem em grande medida à adoção de um estilo de vida globalizado. Isso também pode ser observado nas estratégias de marketing dos empreendedores, que geralmente se referem explicitamente a modelos norte-americanos e obtêm sucesso. Ademais, o controle exclusivo dos espaços pelo capital privado pode ser interpretado como parte integral dos padrões de desenvolvimento urbano, caracterizado pela desregulamentação e flexibilidade, que emergiram na América Latina em face ao neoliberealismo. (Coy e Pöhler, 2002:358 - tradução livre)

O número 29 da revista Environment and Planning B (Webster et alli, 2002), no qual está publicado o texto acima, se denomina um Theme Issue, cujo tema é The global spread of gated communities. A publicação contém artigos de nove autores, em sua maioria geógrafos, que apresentam estudos de caso em diversas partes do globo. Desse grupo inicial se originou uma coletividade que se denominou, originalmente, An international and interdisciplinary research network on gated housing estates as an international phenomenon. A "rede" já realizou diversas conferências, ${ }^{5}$ tendo também organizado outras publicações (Atkinson e Blandy, 2005, 2006; Glasze et alli, 2006).

O que me chamou a atenção, ao ler os artigos da publicação de 2002, foi, por um lado, o fato de todos os autores usarem o termo gated community e citarem Blakely e Snyder. Porém , mais do que a utilização do termo por todos, chamava a atenção a falta de utilização desse termo pelos "nativos" dos estudos de caso. Listo aqui outros termos utilizados nos artigos: fortified enclaves, gated housing estates, extended-family compounds, cultural enclaves, gated settlements; walled communities, fortified villages, enclosed neighborhoods, security villages; condomínios fechados, condomínio exclusivo, barrios privados, barrios cerrados, countries. Não acredito que essa profusão de termos seja simplesmente um reflexo das diferenças linguísticas encontradas em diferentes países, mas sim um indicador de que se trata de fenômenos que, se apresentam alguma generalidade, também têm grandes especificidades locais.

Sob o termo gated community apareciam complexos de apartamentos como os encontrados na Barra da Tijuca, no Rio de Janeiro, bairros construídos para funcionários de construtoras transnacionais em países árabes, conjuntos de casas populares na África do Sul, conjuntos de casas habitados por membros de uma mesma família, bairros com shopping centers e hotéis, ocupando áreas centrais de grandes cidades ou periferias, enfim, uma enorme variedade de configurações espaciais. Não obstante essa relativa confusão, era possível perceber que, na maioria 
das vezes, tratava-se de incorporações imobiliárias dirigidas às elites e camadas médias surgidas, principalmente, a partir da década de 1990, localizadas às margens de cidades de grande e médio porte, com vias de acesso restrito a moradores e um perímetro delimitado por cercas ou muros além de um aparato de segurança privado.

Para grande parte daqueles que se interessam por gated communities, o foco principal de interesse parece ser - para além do ideal de comunidade que já vimos ser uma preocupação central nos EUA - o próprio muro perimetral, que separa o que está dentro do que está fora, produzindo novos padrões de segregação urbana. Os muros passam, então, a ser um novo veículo de organização e significação da cidade. Esse é um dos argumentos de Teresa Caldeira em seu livro Cidade de Muros, que também se tornou uma referência comum entre os que estudam gated communities em outras partes do mundo. É importante notar, no entanto, que, enquanto Caldeira utiliza o termo gated community para se referir aos empreendimentos imobiliários de Los Angeles, o termo utilizado para São Paulo é "condomínio fechado". Ela propõe o termo mais abangente "enclave fortificado" para pensar ambos, incluindo também shopping centers e outros tipos de espaços.

De Johanesburgo a Budapeste, do Cairo à Cidade do México, de Buenos Aires a Los Angeles, processos semelhantes ocorrem: o erguimento de muros, a secessão das classes altas, a privatização dos espaços públicos e a proliferação das tecnologias de vigilância estão fragmentando o espaço da cidade, separando grupos sociais e mudando o caráter da vida pública de maneiras que contradizem os ideais modernos de vida urbana. (Caldeira, 2000:328)

O "ideal moderno de vida urbana" seria representado pelos espaços multifuncionais, com livre circulação de pessoas e encontro de diferenças, caracterizado por cidades como Paris e Londres, ao passo que a queda desse ideal moderno seria representada principalmente pela cidade de Los Angeles que aparece como protótipo de uma chamada pós-modernidade urbana. Essa pós-modernidade pode ser louvada ou atacada, mas é retratada como um fenômeno global. Essa nova cidade contém características que a distingue de cidades como Chicago, por exemplo, que cresceram na época do fordismo industrial. ${ }^{6}$ Em todo o mundo haveria uma tendência de polarização econômica, com barreiras cada vez maiores entre os ricos e os pobres. Peter Marcuse e Ronald Van Kempen, em livro intitulado Globalizing Cities, publicado em 2000, que contém artigos analisando a distribuição espacial de cidades nos Estados Unidos, Europa, Ásia, América do Sul e Austrália, apresentam a seguinte hipótese a respeito de uma nova ordem espacial: 
Existe uma nova ordem espacial das cidades, começando em algum lugar dos anos 1970 em um período frequentemente descrito como o de uma economia globalizante. Enquanto as cidades sempre foram divididas segundo linhas de cultura, função e status, o padrão atual é de uma nova combinação desses fatores, de caráter mais profundo em diversos aspectos. Apesar de variar substancialmente de uma cidade a outra de acordo com o desenvolvimento histórico da forma construída, com estruturas nacionais, econômicas e políticas, o peso relativo das forças envolvidas no desenvolvimento, com o papel da "raça" e etnicidade, e com a posição na economia internacional, há características básicas em comum. Essas características incluem a concentração espacial dentro das cidades de uma nova pobreza urbana, por um lado, e de atividades financeiras de "alto nível" conectadas internacionalmente, por outro, com o aumento de divisões espaciais não só entre ambos, mas também entre segmentos da "classe média" entre os dois. Fronteiras entre as divisões, refletidas em muros físicos e sociais entre elas, estão aumentando. O resultado é um padrão de aglomerados separados de espaços residenciais, criando cidadelas e enclaves protegidos de um lado e guetos restritivos de outro, em uma relação hierárquica uns com os outros. O mercado produz e reproduz essas divisões, mas o Estado está profundamente envolvido na sua criação e manutenção. O Estado também pode melhorá-las, e tenderá a fazê-lo sob condições específicas. O resultado é um padrão convergente nas cidades que é radicalmente diferente de padrões anteriores para justificar que se fale em um "novo padrão espacial”. (Marcuse e Van Kempen, 2000:4-5)

Os artigos do livro dialogam com essa hipótese, procurando compará-la a realidades de cidades que vão de Cingapura ao Rio de Janeiro, passando por Nova Iorque e Bruxelas. Ao final, os autores concluem que sua hipótese não pode ser aplicada ao mundo inteiro, porém há, sim, algumas tendências averiguadas em todas as cidades pesquisadas, principalmente no que se refere ao aumento das divisões espaciais. Eles então enumeram uma lista de 12 mudanças percebidas em nível mundial. Entre elas estão: "O aumento de muros entre regiões da cidade, de cidadelas defensivas a comunidades muradas de renda média e alta até bairros pobres confinados e entrincheirados" e "Edge cities, uma extensão e expansão da suburbanização de residência e trabalho para as classes médias e parte da classe gerencial-profissional" (Marcuse eVan Kempen, 2000:271). ${ }^{8}$ Além dessas tendências gerais, os estudos de caso mostram que há gated communities em Cingapura, Calcutá e Bruxelas.

Nem todas as análises, porém, colocam as gated communities como fenômenos totalmente originários nos EUA. Se a ideia de uma adoção generalizada de um estilo de vida originário nos suburbs dos Estados Unidos é bastante aceita, o elemento "gated", no binômio gated community, muitas vezes é imputado à América Latina. Vejamos um trecho do livro de Setha Low, presidente da American Anthropological Association, sobre gated communities nos Estados Unidos: 
Como estudante de antropologia que se especializou em América Central e Caribe, eu logo aprendi que muros e portões são onipresentes em toda a América Latina. Eles separam o domínio doméstico das mulheres dos domínios públicos dos homens, fornecendo defesas físicas e simbólicas contra intrusos. Cidades e fortalezas antigas da América do Norte, como Roanoke, na Virgínia, também eram inicialmente cercadas por muros e barricadas para proteção. Mas muros e portões jamais se tornaram um aspecto estabelecido no planejamento urbano norte-americano. Ao contrário, os espaços escancarados da fronteira oeste, o democrático "village green" da Nova Inglaterra e as paisagens sem cercas dos subúrbios foram adotados como modelos espaciais." (Low, 2003:111-112)

De modo mais específico, reconhecendo na comparação São Paulo - Los Angeles o valor do esclarecimento recíproco de elementos que se encontram em ambas as cidades, mas estão mais exacerbados em cada uma diferencialmente, Caldeira também coloca o binômio muro/comunidade em uma relação onde o muro se encontra bem mais explícito no caso brasileiro enquanto a comunidade seria um fenômeno praticamente ausente:

Novamente é revelador fazer algumas comparações com os enclaves americanos. Nos Estados Unidos, “community” é uma designação comum para condomínios de vários tipos. Em São Paulo, os incorporadores imobiliários não veem a si mesmos como "community builders", e os anúncios não apresentam os condomínios fechados como um novo tipo de vida comunitária, mas apenas como um local de moradia para grupos sociais homogêneos. (Caldeira, 2000: 226-227)

Se Caldeira, na tese que foi defendida em 1992, enfatizava os muros e a segregação produzida pelos "enclaves fortificados", é possível identificar um processo de adoção generalizada do termo gated community em anos posteriores para além do caso específico norte-americano. Um exemplo interessante dessa adoção, além da própria rede de pesquisadores da qual já tratamos, é o trecho de um trabalho escrito em francês, a respeito de áreas residenciais muradas na Venezuela.

Seja pelo emprego de alfândegas móveis intempestivas das forças de ordem nas principais artérias, pela multiplicação de "pedágios" e de outras formas de faroeste nos bairros pobres, pela emergência de gated communities nas periferias, ou pela instalação de alfândegas residenciais urbanas que privatizam os espaços públicos nos bairros nobres, a sociabilidade citadina se constrói pelos meios e objetivos da vigilância. (Garcia Sanchez, 2006:246 - tradução livre) 
Quando indagado acerca do motivo de ter utilizado o termo gated community, o pesquisador respondeu que havia, de fato, alguns empreendimentos em Caracas, produzidos por empresas norte-americanas identificados por esse termo. ${ }^{9}$ Porém, disse García Sanchez, o motivo principal da opção conceitual foi para poder ter interlocutores na comunidade acadêmica francesa!

\section{Brasília e Goiânia: condomínios em perspectivas}

Como procurei apontar na seção anterior, acredito que um dos problemas de se falar de estilos de vida globalizados e mesmo de usar termos como "gated communities" para designar espacialidades em diversas partes do mundo é produzir uma falsa homogeneização, perdendo não só as particularidades locais, mas a riqueza dos processos por meio dos quais os fenômenos se configuram.

Em trabalhos anteriores, propus, por exemplo, tirar um pouco o foco dos muros como sendo a grande novidade nos padrões de moradia das elites e camadas médias brasileiras e pensar um fenômeno mais restrito, que é a existência de bairros parecidos com as paisagens abertas dos suburbs nas periferias das cidades brasileiras, ainda que essas paisagens tenham seus perímetros definidos por muros e serviços de segurança privada (Patriota de Moura, 2003a, 2003b, 2007a). Mais do que compreender a proliferação de muros, o que me intrigava era saber por que esses quintais gramados, sem muros frontais, passaram a representar visões paradisíacas em nossas cidades. Propus-me a estudar as implicações das escolhas de viver em condomínios horizontais para melhor compreender a situação de alguns setores das camadas médias no Brasil. Por meio do estudo das formas de habitação, entendidas como escolhas efetuadas por sujeitos a partir de projetos elaborados em campos de possibilidades (Velho, 1994), procurei compreender processos sociais mais amplos, evidenciados nas relações estabelecidas tanto dentro dos condomínios como entre os que se encontram dentro e fora de seus muros. Demonstrei que esses condomínios, juntamente com as áreas que os cercam, podem ser interessantes para pensarmos categorias como status, classe e alteridade, assim como processos de segregação social, tópicos que se constituem preocupações clássicas das ciências sociais.

$\mathrm{O}$ que pude verificar na pesquisa feita em Goiânia ${ }^{10}$ é que os condomínios horizontais não eram somente configurações espaciais onde pessoas escolhiam viver. Eles estavam carregados de significados e valorações socialmente compartilhados que os faziam ser novidades desejáveis nas quais as pessoas faziam importantes investimentos materiais e emocionais. Eram esses significados, se não tanto a forma dos projetos arquitetônicos e urbanísticos, que faziam com que a vida em condomínios não fosse simplesmente a adoção de um globalized lifestyle.

Ainda no âmbito da discussão etnográfica feita a partir de dois condomínios horizontais goianienses, pude demonstrar a variedade de realidades presentes em diversos condomínios. Se, por um lado, havia uma referência comum construída 
por meio da publicidade de alguns condomínios de alta renda, cujas imagens se difundiam em outdoors, propagandas de rádio e televisão em horários nobres e revistas que circulavam dentro e fora de um "mundo dos condomínios horizontais", havia também marcantes diferenças entre as famílias abastadas que compravam terrenos contíguos para transformar parentes em vizinhos após décadas de dispersão em diferentes territórios urbanos, e as famílias nucleares recém-chegadas numa classe média, que utilizavam todos os seus recursos para morar em um condomínio horizontal a poucos metros do bairro popular, "de periferia", onde permaneciam parentes menos abastados. Da mesma forma, ao contrário das experiências narradas em outros estudos, a fortificação que pude acompanhar nos condomínios de Goiânia se justificava como medida preventiva e não paliativa e a sensação de clausura se referia muito mais à vida fora do condomínio do que à experiência dos espaços abertos, sem cercas ou muros entre as casas, que o projeto urbanístico dos empreendimentos imobiliários produzia (Patriota de Moura, 2003a, 2006).

Ao me debruçar sobre o caso de Brasília, mais peculiaridades se manifestam. O caso da capital federal permite problematizar ainda mais a questão da homogeneização. É interessante notar, por exemplo, que Goiânia e Brasília, duas cidades originadas a partir de projetos moldados pelas diretrizes modernistas dos CIAM (Congrès Internationaux d'Architecture Moderne), que recomendavam a especialização de funções e o zoneamento especializado a partir de um planejamento total, tenham tido desdobramentos tão diferenciados em termos da ocupação do solo pelas camadas médias e elites. Se em ambas as cidades há a proliferação de condomínios horizontais em áreas periféricas, em Goiânia, os empreendimentos devidamente legalizados são anunciados como obras de modernidade urbanística, planejamento ordenado, sanitário e ecológico em continuidade com o próprio discurso mudancista de Pedro Ludovico na década de 1930 (Patriota de Moura, 2005). Já em Brasília, modelo global de cidade modernista (Holston, 1999), os condomínios são fruto de ocupações clandestinas que envolvem querelas legais não só entre grileiros, Estado e "ingênuos compradores ludibriados", mas entre diversas instâncias públicas distritais e federais, além de litígios sobre titularidade de terras que precedem a própria construção da cidade (Malaguti, 1997; Vianna, 2005; Fortes, 2007; Patriota de Moura, 2007b).

É interessante notar, voltando ao texto do jornal Correio Braziliense, citado no início deste trabalho, que "condomínio", em Brasília, pode também ser sinônimo de parcelamento irregular, efetivando uma transformação interessante: em vez de denominar os condomínios ilegalmente ocupados de "invasões", áreas residenciais de baixa renda que, em outras épocas, eram denominadas invasões e que agora são chamadas de “condomínio". Se, em Goiânia, os condomínios são construídos simbolicamente como espaços paradisíacos pouco contestados, em Brasília o discurso público acerca dos condomínios se atualiza principalmente por meio de vozes dissonantes em um campo de intensos conflitos. 
Ao ser perguntada "o que é um condomínio", a presidente da União dos Condomínios Horizontais e Associações de Moradores no Distrito Federal (Única-DF) responde:

Na realidade, aqui no Distrito Federal, tudo que é um parcelamento tem nome de condomínio, só que poucos na realidade vivem em situação condominial. Por quais motivos? (Em primeiro lugar) Porque ainda não existe uma lei que permita, que tenha, que crie essa figura do condomínio horizontal, a gente está buscando isso há muitos anos, existe um projeto de lei, tramitando lá no Congresso, ainda não existe uma lei específica para condomínio horizontal no Brasil, não existe essa modalidade de parcelamento e é o que vai precisar ser criado e a gente tem uma expectativa que essa lei chegue porque ela já está consolidada. O Brasil inteiro tem condomínios e ainda não tem uma lei específica para isso, não dá porque tem que alterar a Lei $n^{\circ}$ 6.766, que é a Lei de Parcelamento do Solo. Tem que ser alterada e criar essa figura, né? E enquanto isso não acontecer, fica essa situação complicada. Nos estados, em alguns municípios, leis regulamentam essa situação de loteamentos fechados para que isso não ficasse na irregularidade. Aqui no Distrito Federal é uma das poucas localidades que tem uma restrição muito grande a isso. O Ministério (Público) é muito contra a questão do condomínio, principalmente do condomínio fechado. Tem que se entender que hoje nós só estamos mantendo esses muros e guaritas por uma boa vontade, porque lei mandando, estabelecendo que eles possam ficar, ainda não tem.

E para além da situação legal existem os usos do termo condomínio:

Oficialmente existem 513 condomínios no Distrito Federal. A nossa entidade tem um levantamento que não é preciso, porque ainda tem os condomínios que não são condomínios oficialmente, formalmente, nem associações. É um levantamento de 844 entidades, né? Entre condomínios e associações, se você observar ainda tem os que não são formalizados, são muito mais de 1000 (...).

* Mas que se dizem condomínio?

Mas chama de condomínio. Se você chegar "ah, onde você mora?" "moro lá no condomínio das flores lá não sei das quantas”, mas dividem despesa. Não é formalizado, não tem um CNPJ, não tem endereço, não tem CEP. Dividem, rateiam, porque se eles não dividirem eles não dão conta, eles têm que pagar água, têm que coletar lixo, entendeu? Não tem nada formalizado, mas existe. No Distrito Federal, é tão enrolada essa questão de informalização das coisas (...).

(Entrevista realizada em junho de 2008) 
É claro que, como também já pude demonstrar, há conflitos nos condomínios de Goiânia e certamente será possível encontrar sonhos edênicos entre as motivações que levaram pessoas a comprarem terrenos em alguns dos condomínios em Brasília. Não obstante, o que vale notar aqui é que fenômenos urbanos denominados pelo mesmo termo, em duas cidades separadas por apenas 200 quilômetros, em cidades que têm suas gêneses a partir de projetos modernistas no Planalto Central brasileiro, têm significados e dinâmicas de estabelecimento marcadamente distintos. E é nesse sentido que vale perguntar o que significa o termo "condomínio" assim como vale voltar à discussão sobre o termo "gated community" para em seguida refletir acerca das possibilidades de comparação e das formas sociais/espaciais/simbólicas que pretendemos comparar.

\section{As composições urbanas}

Condomínios e gated communities são termos que fazem sentido "em situação" para aqueles interessados nos fenômenos materializados em áreas residenciais privadas, sejam esses residentes, empreendedores, publicitários, prestadores de serviços, governos locais e nacionais. Os termos também fazem sentido para aqueles interessados em compreender esses espaços como fenômenos que compartilham elementos com outros fenômenos, sejam esses da mesma ordem ou de ordem diferente.

A discussão apresentada acima pretendeu mostrar que, se o termo "gated community" é hoje um termo utilizado na literatura acadêmica internacional para designar áreas residenciais em diversas partes do globo, sua origem e trajetória têm importantes implicações teóricas por evocarem referências que não são somente descritivas, mas, como no caso do termo "community", estão carregadas de sentidos com forte carga valorativa. Assim, falar em gated community nos Estados Unidos seria, nos termos de Geertz (1983), falar em termos próximos à experiência dos atores, enquanto falar de gated communities para intelectuais franceses, referindo-se a empreendimentos imobiliários na Venezuela, já seria uma tentativa de conceitualizar um fenômeno distante da experiência. O ponto a ser enfatizado aqui é que, se os termos são gerados em momentos e circunstâncias específicas, sua própria utilização para falar de outras circunstâncias em outros momentos pode acarretar seja uma apreensão do fenômeno como algo homogêneo ou a comparação de fenômenos localizados como se um fosse o modelo e outro uma tentativa mais ou menos bem-sucedida de aproximação ao modelo.

Não é à toa que um termo experience near nos Estados Unidos, como o termo "gated community", se torne tão generalizado para pensar fenômenos que se apresentam com diversos nomes em diversas partes do mundo ${ }^{11}$ e que, mesmo quando compartilham o mesmo nome, como é o caso dos condomínios horizontais em Brasília e Goiânia, encerram processos políticos, econômicos e simbólicos, tecnológicos, legais e mesmo de distribuição espacial extremamente diferenciados. 
Retornando à discussão inicial, não se trata simplesmente de apresentar a particularidade dos "casos" de Brasília ou Goiânia em oposição a um "modelo" global, mas de questionar o próprio modelo, a partir de uma perspectiva teórica que vê na dinâmica dos processos e nas sucessivas combinações de elementos uma importante contribuição para os conhecimentos que formulamos acerca de processos urbanos. Menos do que uma perspectiva holista que perde a visão das partes, mas mantendo alguma noção de totalidade naquela de composição (assemblage), talvez a grande contribuição da etnografia esteja na sua capacidade de apresentar esses processos, acompanhar os atores (Latour, 2005, 2006) e, assim, oferecer um conhecimento que não homogeneíze de antemão, pela própria designação conceitual dos fenômenos.

O termo assemblage, na língua inglesa, vem sendo utilizado na literatura antropológica recente para pensar principalmente fenômenos "globais" contemporâneos que escapam a domínios previamente pensados como tendo fronteiras claras, como questões de biopoderes, por exemplo, que combinam elementos da ciência, política, religião etc. (Ong e Collier, 2005:17-18) Bruno Latour (1993), bem como Deleuze e Guatari (1987) são citados como fontes de inspiração teórica. A monadologia de Gabriel Tarde, por sua vez, é fonte de inspiração tanto para Deleuze ${ }^{12}$ quanto para Latour, principalmente no que se refere a uma concepção do social que se baseia na ideia da multiplicidade dos agentes que se combinam:

O caráter bizarro e disparatado da realidade, visivelmente dilacerada por guerras internas seguidas de transações capengas, supõe a multiplicidade dos agentes do mundo. Sua multiplicidade confirma sua diversidade e somente ela pode lhe conferir uma razão de ser. Nascidos diversos, eles tendem a se diversificar; é sua natureza que o exige. Por outro lado, sua diversidade se deve àquilo que são: não unidades, mas totalidades especiais. (Tarde, 2003:94)

E por “totalidades especiais” Tarde entende as próprias mônadas que, longe de serem unidades indivisas, são sempre combinações provisórias, apesar de dotadas de agência. É essa ideia da diversidade dos agentes que se compõem em "totalidades especiais" que está por trás da ideia de assemblage. Nos termos de Tarde, em francês:

(...) ces élements derniers auxquels aboutit toute science, l'individu social, la cellule vivante, l'atome chimique, ne sont derniers qu'au regard de leur science particulière. Eux mêmes sont composés. ${ }^{13}$ (Tarde, 1999:36)

Os composés de Tarde, assim como os assemblages de Ong e Collier ou mesmo as redes, híbridos e coletivos de Latour ${ }^{14}$ (1993, 2005), são agentes formados por elementos heterogêneos. Proponho, com a discussão aqui iniciada, pensar formas sociais e espaciais a partir de uma perspectiva da composição ou dos compostos. 
Utilizo os termos que se aproximam mais do termo francês encontrado na obra de Tarde acima citada. A heterogeneidade também está no cerne do pensamento de Deleuze que, por sua vez, reconhece a contribuição teórica de Gabriel Tarde. É o conceito de agenciamento (agencement) que tem sido traduzido para o inglês como assemblage e tem servido de base para o que Manuel De Landa (2006) vem chamando de assemblage theory. Acredito que o termo na língua inglesa empresta mais concretude ao conceito do que o termo agenciamento. Tanto os agenciamentos quanto os compostos propõem uma perspectiva a partir da qual é possível perceber o mundo social sem a necessidade de recorrer a distinções ontológicas entre natureza e sociedade, ou agentes humanos e não-humanos. ${ }^{15}$ Os agentes que interagem não são somente pessoas fazendo coisas juntas, mas pessoas, construções materiais, ideias e quaisquer outros elementos que venham interagir.

Pensar os condomínios como composições tem a vantagem de tirar o foco dos contextos - o inatingível "corpo político" mencionado por Latour (2005) - e permitir pensar processos de combinações de fatores transversais. Esses fatores não se resumem nem ao "mundo dos condomínios" (Patriota de Moura, 2003) nem a Brasília, o Brasil, ou mesmo a "globalização neoliberal" que modula processos de apropriação do solo urbano em diversas partes do mundo, mas articulam processos multiescalares (Sassen, 2006), fazendo com que determinadas capacidades sejam mais atuantes que outras. Também permite pensar fenômenos urbanos de uma ótica que vai além de uma oposição entre espaços de fluxos e espaços de lugar e de processos de acirramento da segregação urbana (Castells, 2006; Caldeira, 2000). Não se trata de negar a existência desses processos, mas de pensar as originalidades e diversidades de combinações possíveis.

Trata-se, portanto, de pensar os condomínios horizontais como composições abertas, apesar do fechamento espacial ser uma característica muito comumente associada às espacialidades designadas por tal nome. Entendo-os sob a ótica da composição, torna-se possível reter as vantagens da perspectiva comparativa no sentido de que os estudos sobre gated communities podem ajudar a esclarecer processos e características identificados nos estudos etnográficos realizados em condomínios em diferentes cidades brasileiras. Não se trata, no entanto, de comparar totalidades fechadas ou mesmo traços específicos de formas sociais análogas, mas de pensar a maneira como elementos se associam uns aos outros em processos que geram fenômenos singulares.

A heterogeneidade e capacidade de sobreposição de diferentes dimensões (material, espiritual, econômica, política, simbólica e o que mais quisermos nomear) têm chamado a atenção de diferentes gerações de autores que se debruçaram sobre o tema da vida urbana. As dinâmicas urbanas contemporâneas, como nos ensina Saskia Sassen, combinam elementos que operam em diferentes escalas, mas 
essas escalas não se encaixam necessariamente umas nas outras, como círculos concêntricos ou bonecas russas. Os condomínios situados no Distrito Federal ou em Goiânia não podem ser compreendidos somente a partir de sua "inserção" nos processos locais (ou regionais) de expansão urbana. Tampouco são explicáveis por meio de sua vinculação automática a fenômenos "globais", como sugere a utilização do termo gated community. Relacioná-los ao aumento dos índices de violência nos grandes centros urbanos do Brasil ou a preferências "culturais" latino-americanas por muros também não basta. Todas essas “paisagens”, no entanto, são relevantes para percebermos processos particulares que se fazem presentes nos mundos vividos ${ }^{16}$.

$\mathrm{O}$ argumento deste artigo se sustenta no princípio de que a comparação de fenômenos análogos é importante e frutífera, mas a construção de "tipos" e "modelos" aos quais "casos" se tornam automaticamente referenciáveis mascara mais do que elucida. A proposta de pensarmos formações urbanas como composições multiescalares é uma aposta no sentido de torná-las mais inteligíveis sem tratá-las como manifestações imperfeitas de "realidades" homogêneas. Postular a singularidade absoluta, por outro lado, também incorre no risco de apagar vetores homogeneizantes que porventura atuem nas composições. Assim, talvez uma antropologia das composições urbanas que perceba etnograficamente alguns dos intricados meandros por meio dos quais nossas cidades se formam possa contribuir de maneira relevante para os estudos urbanos em geral.

\section{Notas}

* Esta é uma versão revista do trabalho intitulado "Condomímios Fechados e Gated Comunities: umas discussão conceitual”, apresentado no $31^{\circ}$ Encontro Anual da ANPOCS, de 22 a 26 de outubro de 2007, Caxambu, MG, no ST 5 - Cidades: perspectivas e interlocuções nas ciências sociais.

1. Ver Sanchez e Lang (2002) e Low (2003).

2. No livro The Moral Order of a Suburb, Mary Baumgartner afirma que, nos suburbs norte-americanos produziram um tipo específico de ordem moral, que ela denomina de "minimalismo moral":

"People in the suburbs live in a world characterized by nonviolence and nonconfrontation, in which civility prevails and disturbances of the peace are uncommon. In this sense, suburbia is a model of social order. The order is not born, however, of conditions widely perceived to generate social harmony. It does not arise from intimacy and connectedness, but rather from some of the very things more often presumed to bring about conflict and violence transiency, fragmentation, isolation, atomization, and indifference among people. The suburbs lack social cohesion but they are free of strife. They are, so to speak, disorganized and orderly at the same time." (Baumgartner, 1988:134) 
3. É interessante notar que, ironicamente, a Associação Americana de Sociologia publica o periódico City and Community, enquanto a American Anthropological Association publica City and Society, invertendo divisões clássicas segundo as quais a antropologia estudaria comunidades menores enquanto a sociologia estudaria "sociedades".

4. Ver Jacobs (1961), Duaney et alli. (2000), Jackson (1985) e Gans (1993).

5. Mainz, 2002; Glasgow, 2003; Nova Orleans, 2004; Pretoria, 2005; Paris, 2007; Santiago, 2009. Ver http://www.gated-communities.de/. O mesmo grupo , que se autodenomina "An international and interdisciplinary research network on gated housing estates as an international phenomenon", se reuniu em junho de 2002, no Instituto de Geografia da Universidade de Mainz, na Alemanha, onde houve uma International Conference on Private Urban Governance e em Glasgow, na Escócia, em outubro de 2003.

6. Ver, a esse respeito, Harvey (1992), Davis (1990), Abu-Lughod (1999), Castells (2002, 2006), Sassen (1991, 2006).

7. "Increasing walling among the quarters, from defensive citadels to gated upper and middle income communities to confined and barricaded poor neighborhoods."

8. "Edge" quer dizer margem, borda, beirada.

9. Comunicação oral em seminário apresentado no Departamento de Antropologia da UnB em 19/09/2007.

10. Refiro-me aqui à minha tese de doutorado (Patriota de Moura, 2003b).

11. Os trabalhos mais recentes de Mariza Peirano também questionam as categorias e classificações da própria antropologia, em continuidade com sua visão antropológica dos antropólogos e do estabelecimento (e pulverização) da disciplina em países como Brasil, Índia e Estados Unidos. É interessante que Peirano fale do papel proeminente dos Estados Unidos no campo das definições institucionais, bem como da produção e mercado acadêmicos, que ela considera "socialmente equivalente ao da Inglaterra durante a primeira metade do século XX, ou da França nos momentos áureos do Estruturalismo.” (Peirano, 2006: 39)

12. "Ninguém soube melhor que Tarde elaborar uma nova dialética, descobrindo, na natureza e no espírito, o esforço secreto para instaurar uma adequação cada vez mais perfeita entre a diferença e a repetição.” (Deleuze, 2006:52)

13. "Esses elementos últimos em que culmina toda ciência, o indivíduo social, a célula viva, o átomo químico, só são últimos em relação à sua ciência particular. Eles mesmos são compostos." (tradução minha)

14. Latour também utiliza o termo assemblage quando escrevendo em inglês, apesar de não remeter esse termo à ontologia deleuziana. "We can already conclude that the social, as usually defined, is but a moment in the long history of assemblages, suspended between the search for the body politic and the exploration of the collective." (Latour, 2005: 247)

15. Nesse sentido, os compostos vão além da ideia de mundos em Howard Becker (1982, 2006), que utilizei para pensar os condomínios horizontais em Goiânia (Patriota de Moura, 2003). Os agentes que interagem não são somente pessoas fazendo coisas juntas, mas pessoas, construções materiais, ideias e quaisquer outros elementos que venham interagir.

16. Para um exercício nesse sentido, que procura identificar elementos e composições presentes na dinâmica dos condomínios de Brasília, ver Patriota de Moura. 


\section{Referências bibliográficas}

ANDRADE, Luciana Teixeira de. 2001. "Condomínios Fechados na Região Metropolitana de Belo Horizonte: novas e velhas experiências”. In: IX Encontro Nacional da ANPUR. Ética, Planejamento e Construção Democrática do Espaço. Anais. Rio de Janeiro: IX Encontro Nacional da ANPUR. vol. II. 28 abr. a 01 jun. 2001

ATKINSON, Rowland \& BLANDY, Sarah. 2006. Gated Communities. London: Routledge.

ABU-LUGHOD, Janet L. 1999. NewYork, Chicago, Los Angeles. America’s Global Cities. Minneapolis: University of Minnesota Press.

ATKINSON, Rowland \& BLANDY, Sara. 2005. "Introduction: International Perspectives on the New Enclavism and the Rise of Gated Communities”. Housing Studies, . 20(2).

BAUMAN, Zigmunt. 2003. Comunidade. A busca por segurança no mundo atual. Rio de Janeiro: Zahar.

BAUMGARTNER, Mary P. 1988. The Moral Order of a Suburb. New York: Oxford University Press.

BLAKELY, Edward J. \& SNYDER, Mary Gail. 1997. Fortress America: Gated Communities in the United States. Washington D.C./Cambridge Mass.: Brookings Institutions Press/Lincoln Institute of Land Policy.

BLANDY, Sarah. 2003. "Gated communities: (Ne)gating community development?", paper apresentado na conferência Gated communities: building social barriers or better safer communities? University of Glasgow. 17 e 18 out. 2003.

CALDEIRA, Teresa Pires do Rio. 2000. Cidade de Muros: crime, segregação e cidadania em São Paulo. São Paulo: Editora 34/EdUSP.

CASTELLS, Manuel. 2006 [1999]. “O Espaço de Fluxos”. In: A Sociedade em Rede. Rio de Janeiro: Paz e Terra. pp.467-522

CASTELLS, Manuel. 2002. "The City in the Information Age". In: The Castells Reader in Cities and Social Theory. New York: Blackwell Publishers. pp. 367-389

CORREAA DO LAGO, Luciana. 2002. "A lógica segregadora na metrópole brasileira: novas teses sobre antigos processos". Cadernos do IPPUR, Planejamento e Território. Ensaios sobre a desigualdade. 155-176.

COY, Martin \& PÖHLER, Martin. 2002. "Gated Communities in Latin American Megacities: case studies in Brazil and Argentina". Environment and Planning B: Planning and Design, 29(3): 355-370. Theme issue: The global spread of gated communities. London: Pion Limited.

DA MATTA, Roberto. 1974. "O ofício do etnólogo, ou como ter anthropological blues”. Cadernos do PPGAS. Rio de Janeiro: Museu Nacional. 
DAVIS, Mike. 1990. City of Quartz. Excavating the Future in Los Angeles. London: Verso.

DE LANDA, Manuel. 2006. A New Philosophy of Society. Assemblage theory and social complexity. New York: Continuum Books.

DELEUZE, Gilles. 2006 [1968]. Diferença e Repetição. São Paulo: Graal.

DELEUZE, Gilles \& GUATARI, Felix. 1980. Mille Plateaux. Paris: Les Éditions de Minuit.

DUANEY, Andrés; PLATER-ZYBERK, Elizabeth \& PECK, Jeff. 2000. Suburban Nation. The Rise of Sprawl and the Decline of the American Dream. New York: North Point Press.

DUNDAR, Oslem. 2003. “An example of a gated community from Ankara, Turkey”. Comunicação apresentada na conferência Gated communities: building social barriers or better safer communities? University of Glasgow. 17 e 18 out. 2003.

ECKERT, Cornélia \& CARVALHO DA ROCHA, Ana Luiza. 2005. “A Cidade e o Medo como Drama Social”. Mimeo.

FALZON, Mark-Anthony. 2004. "Paragons of Lifestyle: gated communities and the politics of space in Bombay". City \& Society, 16(2): 145-167.

FORTES, Paulo; Barroso, Edson; Silva, Maria Alice e Guedes, Carlos Otávio. 2007. "Regularização fundiária em imóveis da União no Distrito Federal". In: Anais XIII Simpósio Brasileiro de Sensoriamento Remoto. Florianópolis, 21 a 26 abr. 2007.

FRÚGOLI Jr., Heitor. 2005. "O urbano em questão na antropologia: interfaces com a sociologia”. Revista de Antropologia, 48(1): 133-165.

GARCIA, Pedro José \& VILLÁ, Marc. 2001. "De la Sociabilidad Vigilante a la Urbanidad Privativa”. Perfiles Latinoamericanos: La Nueva Segregación Urbana. 57-82

GARCIA SANCHEZ, Pedro Jose (2006) "Ressources et dilemmes de la vigilence. Des épreuves du trouble ordinaire à la sociabilité de surveillance“. In: Roux, J. (org.). Etre vigilant. L’opérativité discrete de la societé du risque. Saint-Etienne: Editions de Lúniversité do Saint Etienne.

GANS, Herbert J. 1962. The Urban Villagers: group and class in the life of Italian-Americans. New York: Free Press of Glencoe.

1982. The Levittowners: ways of life and politics in a new suburban community.

New York: Columbia University Press. 1993. People, Plans and Policies. New York: Columbia University Press.

GARREAU, Joel. 1991. Edge City: Life on the new frontier. Nova Iorque: Doubleday. . 2002. "O Sonho Americano". In: Veja on-line. http://www2.uol.com.br/veja/ idade/exclusivo/150502/entrevista.html

GEERTZ, Clifford. 1983. Local knowledge. Nova York: Basic Books. 
GIGLIA, Angela. 2003. "Gated communities in Mexico City", Comunicação apresentada na conferência Gated communities: building social barriers or better safer communities? University of Glasgow. 17 e 18 out. 2003.

GIDDENS, Anthony. 1991. As Consequências da Modernidade. São Paulo: Editora Unesp.

GIROIIR, Guillaume. 2003. "The gated community as a system of clubs. The case of Beijing and Shanghai". Comunicação apresentada na conferência Gated communities: building social barriers or better safer communities? University of Glasgow. 17 e 18 out. 2003.

GLASSNER, Barry. 2003 [1999]. Cultura do Medo. São Paulo: W11 Editores Ltda.

GLASZE, Georg; Webster, Chris e Frantz, Klaus 2006. Private Cities. Global and Local Perspectives. London: Routledge.

GOLDMAN, Márcio. 2000. Do ponto de vista não-nativo: sobre a incompreensão antropológica ou os tambores dos mortos e os tambores dos vivos. Comunicação apresentada no seminário temático A Antropologia e seus Métodos: o Arquivo, o Campo, os Problemas. XXV Encontro Anual da Anpocs, Caxambu.

HANNERZ, Ulf. 1980. Exploring the City. New York: Columbia University Press. .1992. “The Global Ecumene”. In: Cultural Complexity. Studies in the social organization of meaning. New York: Columbia University Press.

HARVEY, David. 1992. Condição Pós-Moderna. São Paulo: Edições Loyola.

HOLSTON, James. (org.). 1999. Cities and Citizenship. Durkam and London: Duke University Press.

JACOBS, Jane. 1961. The Death and Life of Great American Cities. New York: Random House.

JACKSON, Kenneth T. 1985. Crabgrass Frontier: The suburbanization of the United States. Nova Iorque: Oxford University Press.

KUPPINGER, Petra. 2004a. "Introduction: Exploring Urban Segregation". City \& Society, $16(2): 5-9$.

. 2004b. "Exclusive greenery: new gated communities in Cairo". City \& Society, 16(2): 35-61.

LACARRIEU, Monica \& GIROLA, Maria Florencia. 2007. "Modelos globales, processos locales: uma mirada etnográfica sobre el urbanismo electivo y la ciudad-fragmento em la Región Metropolitana de Buenos Aires”. Paper apresentado na LASA's XXVII International Congress, Montreal, set. 2007.

LATOUR, Bruno. 2005. Reassembling the Social. An introduction to Actor-Network-Theory. Oxford: Oxford University Press. 
2006. Livre Virtuel. Paris, Ville Invisible. http://www.bruno-latour.fr/virtual/index.

html\#

LOW, Setha M. 2003 [2000]. "The Edge and the Center: Gated communities and the discourse of Urban Fear". In: Low, Setha; Lawrence-Zúniga, Denise (orgs.). The Anthropology of Space and Place. Blackwell Publishing Company.

2003. Behind the Gates. Life, security and the pursuit of happiness in fortress America. New York: Routledge.

. 2009. "Working with anthropological, psychological and political theories to understand the social consequences of private governance for middle class housing." Comunicação apresentada na Fifth International Conference of the Research Network Private Urban Governance and Gated Communities. Santiago, Chile.

LYNCH, Owen. 1994. "Urban Anthropology, Postmodernist Cities and Perspectives". City and Society, 7(1):35-52.

MACEDO, José Eduardo Ribeiro. 2002. Condomínios Horizontais Fechados: desqualificadores do espaço público? O caso de Goiânia. Dissertação de Mestrado em Sociologia, UFG/FCHF.

McKENZIE, Evan. 1994. Provatopia: Homeowner Assossiations and the rise of residential private government. New Haven: Yale University Press.

MAGNANI, José Guilherme Cantor. 2002. "De perto e de dentro: notas para uma etnografia urbana”. Revista Brasileira de Ciências Sociais, 17(49): 11-29.

MALAGUTTI, Cecília Juno. 1997. "Novas opções de moradia no DF: condomínios ou loteamentos fechados?". Agora. O Espaço de debate das cidades, 1(1): 159-184. Brasília: ASSIP.

MARCUSE, Peter \& VAN KEMPEN, Ronald (orgs.). 2000. Globalizing Cities. A newspatial order? Oxford: Blackwell Publishers.

ONG, Aihwa \& COLLIER, Stephen. 2005. "Global Assemblages, Anthropological Problems”. In: Ong, Aihwa; Collier, Stephen (orgs.). Global Assemblages. Technology, politics and ethics as anthropological problems. Oxford: Blackwell Publishing.

PATRIOTA DE MOURA, Cristina. 2003a. "Gates and Open Spaces: new arrangements in Brazil” Comunicação apresentada na conferência Gated communities: building social barriers or better safer communities? University of Glasgow. 17 e 18 out. 2003.

. 2003b. Ilhas Urbanas: novas visões do paraíso. Uma discussão etnográfica dos condomínios horizontais. Tese de Doutorado, Museu Nacional/UFRJ.

. 2003c. "Vivendo entre Muros: o sonho da Aldeia". In: Velho, Gilberto; Kushnir, Karina. Pesquisas Urbanas. Desafios do trabalho antropológico. Rio de Janeiro: Zahar.

. 2005. "Visionários da Cidade. Considerações sobre o ideal de modernidade em diferentes tempos de produção do espaço urbano goianiense”. Revista Plurais, Vol 1 n.2, PP. 59-77. Anápolis: Universidade Estadual de Goiás. 
. 2006. "A Fortificação preventiva e a Urbanidade como Perigo". Brasília: Série Antropologia, 407.

.2007 . "Onde Mora o Perigo: medo e transgressão em um condomínio horizontal". Comunicação apresentada na First International Conference of Young Urban Researchers. Lisboa, 11 e 12 jun. 2007.

. 2007b. "Gated Communities in the Aftermath of Modernist Planning: Brasília and Goiânia” Comunicação apresentada na LASA's XXVII International Congress: Montreal. set. 2007.

. 2010. "Condomínios Horizontais em Brasília: elementos e composições". Antropolítica n 29, $2^{\circ}$ semestre 2010. No prelo.

PEIRANO, Mariza. 1995. A favor da etnografia. Rio de Janeiro: Relume-Dumará.

. 2006. A Teoria Vivida e outros ensaios de antropologia. Rio de Janeiro: Jorge

Zahar Editor.

PRADO, Rosane Manhães. 1993. Mitologia eVivência da Cidade Pequena nos Estados Unidos. Tese de Doutorado, Museu Nacional/UFRJ.

RABINOW, Paul. 2005. "Midst Anthropology's Problems". In: Ong, Aihwa; Collier, Stephen (orgs.). Global Assemblages. Technology, politics and ethics as anthropological problems. Oxford: Blackwell Publishing.

RAPOSO, Rita. 2003. "The social construction or the symbolic dimension of gated housing estates”. Comunicação apresentada na conferência Gated communities: building social barriers or better safer communities? University of Glasgow. 17 e 18 out. 2003.

ROBERTS, Ana Mércia Silva. 2002. Cidadania Interditada: um Estudo de Condomínios Horizontais Fechados.Tese de Doutorado, Unicamp.

ROMIG, Kevin. 2005. "Upper Sonoran Lifestyle: Gated Communities in Scottsdale, Arizona". City \& Community 4(1): 67-86.

RYLE, Robin R. \& ROBINSON, Robert. 2005. "Ideology, Moral Cosmology, and Community in the United States". City \& Community, 4(1):53-69.

SANCHEZ, Thomas W. \& LANG, Robert E. 2002. Security versus status: The two worlds of gated communities. Census Note 02:02 (November 2002) Metropolitan Institute at Virginia Tech.

SASSEN, Saskia. 1991. The Global City. Princeton: Princeton University Press. . 2006. Territory, Authority, Rights. From Medieval to Global Assemblages. Princeton: Princeton University Press.

SILVA, Rosana Fernandes da. 2003. Condomínios Horizontais Fechados em Goiânia. Um caso: Prive Atlântico. Dissertação de Mestrado, Faculdade de Ciências Humanas e Filosofia, UFG. 
SVAMPA, Maristella. 2001. Los que Ganaron. La vida em los countries e barrios privados. Buenos Aires: Editorial Biblos.

TARDE, Gabriel. 2007 [1895]. "Monadologia e Sociologia”. In: Monadologia e Sociologia. São Paulo: CosacNaify.

VELHO, Gilberto. 1989 [1973]. A Utopia Urbana: um estudo de antropologia social. Rio de Janeiro: Zahar. 1999 [1974]. “Estigma e comportamento desviante em Copacabana”. In: Desvio e Divergência. Uma crítica da patologia social. Rio de Janeiro: Zahar.

. 1981. “Observando o Familiar”. In: Individualismo e Cultura. Rio de Janeiro: Zahar. . 1996. "Violência, reciprocidade e desigualdade: uma perspectiva antropológica". In: Velho, Gilberto \& Alvito, Marcos (orgs.). Cidadania eViolência. Rio de Janeiro: UFRJ/Ed. da Fundação Getúlio Vargas.

VELHO, Gilberto. (org.). 1999. Antropologia Urbana. Cultura e Sociedade no Brasil e em Portugal. Rio de Janeiro: Jorge Zahar Editor.

2002. Mudança, Crise e Violência. Política e cultura no Brasil contemporâneo. Rio de Janeiro: Civilização Brasileira.

VIANNA, Rejane. 2005. Novos santuários de segregação sócio-espacial. Disser tação de Mestrado, Faculdade de Arquitetura e Urbanismo da Universidade de Brasília.

WALDROP, Anne. 2004. "Gating and Class Relations: the case of a New Delhi "colony"'. City \& Society, 16(2): 93-116.

WEBSTER, Chris. 2001. "Gated Cities of Tomorrow”. Town Planning Review 72(2) : 149-70.

2002. "Property rights and the public realm. Gates, green belts and gemeinshaft". Environment and Plannig B: Planning and Design 29(3): 397-412.

WEBSTER, Chris; Glasze, Georg; e Frantz, Klaus (eds) . 2002. Environment and Planning B: Planning and Design 2002 Volume 29 Number 3 may. Theme issue: The global spread of gated communities London: Pion Limited.

\section{Artigos de jornais}

Correio Braziliense (22/08/2006) Um novo perfil. Cidades. pp. A-23 


\section{Resumo}

O presente artigo discute a utilização de termos como "gated communities" e "condomínios horizontais" para caracterizar configurações espaciais específicas que vêm surgindo em áreas metropolitanas em diversas áreas do globo. O objetivo é problematizar esses rótulos em termos dos processos de composição espacial e discursiva dessas realidades materiais e simbólicas. Propõe-se a utilização da noção de composição multiescalar para pensar possibilidades de comparação entre estes fenômenos singulares. A revisão bibliográfica se relaciona à pesquisa de campo feita em "condomínios" nas cidades de Goiânia e Brasília.

\section{Palavras-chave}

Condomínios horizontais, gated communities, composições multiescalares.

\section{Abstract}

The present article discusses the use of terms such as "gated communities" and "condomínios horizontais" to characterize specific spatial configurations which have been rising in metropolitan areas throughout the globe. The aim is to problematize these labels in terms of the processes of spatial and discursive assemblages of these material and symbolic realities. We propose the use of the notion of multiscalar assemblages in order to think about possibilities of comparison between unique phenomena. The review is referred to fieldwork done in "condomínios" in the cities of Goiânia and Brasília.

\section{Key words}

Gated communities, condomínios horizontais, multiscalar assemblages 